Trường Đại học Y Dược, Đại học Quốc gia Hà Nội cho đề tài cơ sở mã số CS.20.06 và Bệnh viện $\mathrm{E}$ đã ủng hộ và tạo điều kiện cho chúng tôi để thực hiện nghiên cứu này.

\section{TÀI LIÊU THAM KHẢO}

1. Nguyen Bich Ngoc, Zhou Lu Lin và Waqas Ahmed (2020), "Diabetes: What challenges lie ahead for Vietnam?", Annals of global health. 86(1).

2. Harold Brem ${ }^{1}$, Marjana Tomic-Canic (2007), "Cellular and molecular basis of wound healing in diabetes", J Clin Invest ;117(5).

3. Daniela Boehm và Paula Bourke (2019), "Safety implications of plasma-induced effects in living cells - a review of in vitro and in vivo findings", Biol. Chem ; 400(1): 3-17.

4. Christian Wetzler và các cộng sự (2000), "Large and sustained induction of chemokines during impaired wound healing in the genetically diabetic mouse: prolonged persistence of neutrophils and macrophages during the late phase of repair", Journal of Investigative Dermatology. 115(2): 245-253.

5. Anita B Roberts (1995), "Transforming growth factor- $\beta$ : activity and efficacy in animal models of wound healing", Wound Repair Regeneration. 3(4): 408-418.

6. S Fathollah và cộng sự (2016), "Investigation on the effects of the atmospheric pressure plasma on wound healing in diabetic rats", Scientific reports. 6(1):1-9.

7. Shahriar Mirpour và cônng sứ (2020), "Cold atmospheric plasma as an effective method to treat diabetic foot ulcers: A randomized clinical trial", Scientific Reports. 10(1): 1-9.

8. Apirag Chuangsuwanich và cộng sự (2016), "The healing effect of low-temperature atmospheric-pressure plasma in pressure ulcer: a randomized controlled trial", The international journal of lower extremity wounds.15(4): 313-319.

\title{
ĐÁNH GIÁ KẾT QUẢ TAO HÌNH VÁ Vỡ XƯƠNG SÀN HốC MẮT THÌ ĐẦU
}

\section{TÓM TẮT}

Mục tiêu: Nhằm hạn chế những di chứng sau chân thương của võ̃ xưởng ổ mắt, chúng tôi đã thực hiện tái tạo lại xương sàn ổ mắt cho bệnh nhân trong thì đầu phẫu thuật. Chúng tôi tiến hành nghiên cứu vể thời gian phẫu thuật, chất liệu tạo hình và đánh giá kết quả tạo hình sàn hốc mắt thì đâu tại bệnh viện Việt Đức. Đối tượng và phương pháp: Nghiên cứu mổ tả lâm sàng cắt ngang dựa trên 48 trường hợp bị vỡ xương sàn hốc mắt sau chấn thương, do mol nguyên nhân, được phẫu thuật tạo hình sàn hốc mắt thì đâu tai Bênh viện Việt Đức, thời gian từ tháng 1 năm 2019 đến tháng 12 năm 2020.Đánh giá kết quả dựa trên chức năng và thẩm mỹ của bệnh nhân. Kết quả: Từ tháng 01/2019 đến 12/2020 tiến hành phẫu thuật tạo hình sàn hốc mắt sớm thì đâu cho 48 bệnh nhân. Tỷ lệ nam/nữ: 36/12, độ tuổi trung bình là 27. Kết quả chụp cắt lớp trước phẫu thuật với độ nhố nhãn câu bên vỡ xương sàn hốc mắt: $13,2 \pm 4,14$ mm; Độ nhô nhãn câu bên lành: $16,61 \pm 2,81 \mathrm{~mm}$, có sự khác biệt trên $2 \mathrm{~mm}$. Kết quả sau phâu thuật: cân xứng ổ mắt đạt $79,2 \%$, mức độ hài lòng của bệnh nhân đạt $85,4 \%$. Kết luận: Võ̃ xương sàn hốc mắt là tổn thương phức tạp cần được can thiệp càng sớm càng tốt. Tạo hình ô mắt ngay thì đầu giúp mang lại hiệu quảvề chức năng và thẩm mỹ cho bệnh nhân.

*Bệnh viện Việt Đức

Chịu trách nhiệm chính: Bùi Mai Anh

Email: drbuimaianh@gmail.com

Ngày nhận bài: 4/6/2021

Ngày phản biên khoa học: 1/7/2021

Ngày duyệt bài: 25/7/2021
Bùi Mai Anh*, Trần Ngọc Vân*, Trần Xuân Thạch*, Vũ Trung Trực*

Từ khoá: Võ xương sàn hốc mắt, lõm ổ mắt, tạo hình ổ mắt

\section{SUMMARY \\ OUTCOMES OF EARLY RECONSTRUCTION OF ORBITAL FRACTURE}

Objectives: To limit the post-traumatic sequelae of orbital fracture, we performed reconstruction of the orbital floor for the patient in the early stages of surgery. We conducted a study on surgery time and materials and evaluated orbital floor reconstruction results at Viet Duc University Hospital. Patients and methods: A cross-sectional descriptive clinical study based on 48 cases of fractured orbital floor bone after trauma, due to all causes, underwent orbital floor reconstruction surgery at Viet Duc University Hospital, the period from January 2019 to December 2020 . Results: From January 2019 to December 2020, an early orbital floor reconstruction surgery was performed for 48 patients. Male/female ratio: 36/12, mean age was 27. Preoperative, the computed tomography with the ocular protrusion on broken orbital floor bone: $13.2 \pm 4.14 \mathrm{~mm}$; Protrusion of the normal side: $16.61 \pm 2.81 \mathrm{~mm}$, with a difference of more than $2 \mathrm{~mm}$. Results after surgery: orbital symmetry reached $79.2 \%$, patient satisfaction reached $85.4 \%$. Conclusion: Fracture of the orbital floor bone is a complex injury that needs to be intervened as soon as possible. Shaping the orbit right at the head helps bring functional and aesthetic effects to the patient.

Keywords: Orbital fracture, reconstruction, material

I. ĐẶT VẤN ĐỀ

Khái niệm võ̃ xương sàn hốc mắt được đề ra 
lần đầu vào năm 1952 bởi sự tăng áp lực thuỷ tĩnh trong nhãn cầu do võ xương. Võ̃ xương sàn hốc mắt có thể đơn thuần hay tổn thương phối hợp với các gãy xương hàm mặt khác. Rất nhiều chấn thương hàm mặt có thể kèm theo chấn thương ổ mắt: Gãy xương hàm trên,Gãy phức hợp xương gò cung tiếp, hoặc Gãy khối mũi sàng. Việc đánh giá chính xác tổn thương thời điểm can thiệp và lập kế hoạch điều trị đòi hỏi phẫu thuật viên nhiều kinh nghiệm

Đa số các tác giả đều cho rằng nên can thiệp sớm trong vòng 2 tuần đầu sau chấn thương sẽ làm giảm hiện tượng teo các tổ chức phần mềm quanh nhãn cầu mặc dù lúc này mắt còn nề, các dấu hiệu như lõm ổ mắt, song thị chưa rõ ràng. Hầu hểt các phẫu thuật nên thực hiện sau 24-48 $\mathrm{h}$ sau chấn thương lúc này hiện tượng phù nề đã giảm bớt $[7,8]$. Có rất nhiều quan điểm về việc sử dụng loại các vật liệu tái tạo sàn ổ mắt như: ghép xương tự thân -sử dụng bản ngoài xương sọ, xương mào chậu, sụn sườn, mesh titan hay medpore... [3,4,8] Việc lựa chọn sử dụng vật liệu tái tạo sàn ổ mắt nào phụ thuộc vào đặc điểm của từng tổn thương. Những năm gần đây, tai bệnh viện Việt Đức phẫu thuật tái tạo lại sàn ổ mắt ngay ở thì đầu được các bác sĩ thực hiện gần như thường quy. Chúng tôi tiến hành nghiển cứu với mục đích đánh giá về thời gian phẫu thuật, chỉ định, chất liệu tạo hình và kết quả tạo hình sàn hốc mắt thì đầu tại bệnh viện Việt Đức.

\section{II. ĐỐI TƯƠNGG VÀ PHƯƠNG PHÁP NGHIÊN CỨU}

Chúng tôi nghiên cứu mô tả lâm sàng cắt ngang trên 48 trường hợp bị võ̃ xương sàn hốc mắt sau chấn thương, do mọi nguyên nhân, lấy ngẫu nhiên cả nam và nữ được phẫu thuật tại bệnh viện Việt Đức, thời gian từ tháng 1 năm 2019 đến tháng 12 năm 2020.

Khám lâm sàng và chẩn đoán hình ảnh: Đây là 02 yếu tố quan trọng cho việc chỉ định phâuu thuật tạo hình sớm ổ mắt thì đầu.

- Khám lẩm sàng bệnh nhân (BN): kiểm tra đối xừng bằng tay tìm các điểm gãy xương quanh ổ mắt, các thử nghiệm vận động nhãn câu, thử nghiệm song thị, đánh giá độ lõm ổ mắt, xuất huyết kết mạc... Đa phần bệnh nhân có các tổn thương gãy xương phối hợp khác hay gặp nhất là gẫy phức hợp gò má ổ mắt.

- Chẩn đoán cận lâm sàng: chụp phim cắt lớp xác định tổn thương. Đánh giá trên phim CT scan lớp cắt ngang 02 chỉ số: Độ nhô nhãn cầu 02 bên và đường kính trong ổ mắt (Dựa trên kỹ thuật của Hacking-2019) [8].

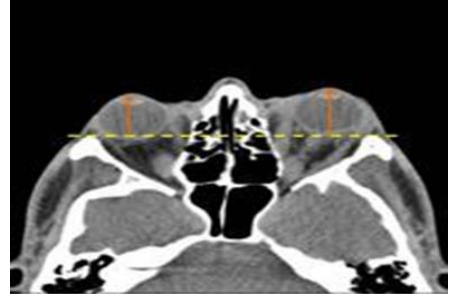

Hinh 1. Độ nhô nhãn cầu theo Hacking

Thông thường hai nhãn cầu sẽ nằm $2 / 3$ phía trước và $1 / 3$ phía sau cảu đường thẳng này. Đo khoảng cách từ đường thẳng này đến điểm cực trước 02 nhãn câuu để tính độ lồi nhãn cầu. Ở người lớn bình thường độ nhô $<19 \mathrm{~mm}$, ở trẻ em độ nhô bình thường < $17 \mathrm{~mm}$. Nếu độ nhô 02 nhãn cầu chênh lệch $>2 \mathrm{~mm}$ là bất thường và cần can thiệp. Trong nghiên cứu này chúng tôi tiến hành đo thêm đường kính trong của ổ mắt (được tính từ thành ngoài của ổ mắt đến thành trong của ổ mắt trên lớp cắt ngang) cả 02 bên nhãn cầu để so sánh.

Bệnh nhân có chỉ định phẫu thuật tạo hình thì đầu sàn ổ mắt dựa trên:

- Lâm sàng: sưng nề bầm tím quanh ổ mắt, hạn chế vận động mắt khi nhìn lên nhìn xuống, nhìn đôi, giảm thị lực, khí dưới da xung quanh ố mắt, xuất huyết kểt mạc. Trong những trường hợp cần thiết bệnh nhân cần khám chuyên khoa mắt trước phẩu thuật.

- Cận lâm sàng dựa trên phim chụp cắt lớp: Nếu độ nhô 02 nhãn cầu và đường kinh trong của 02 ổ mắt chênh lệch $>2 \mathrm{~mm}$ là bất thường và cần can thiệp.

\section{Trình tự phẫu thuật}

- Bệnh nhân được gẩy mê dưới nội khí quản

- Kết hợp xương hàm trên - gò má kèm theo nếu có.

- Đường vào sàn ổ mắt qua đường bờ $\mathrm{mi}$ dưới hoăcc đường kết mạc. Bộc lộ sàn ổ mắt, đánh giá trực tiếp mức độ tổn thương, diện khuyết xương.

- Nâng toàn bộ tổ chức quanh nhãn câu thoát vị.

- Tạo hình che phủ diện khuyết xương bằng mesh titan, xương tự thân hoặc Medpor.

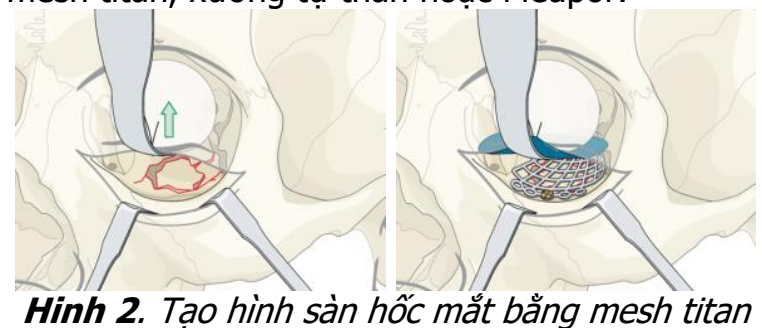

Hinh 2. Tạo hinh sàn hốc mát băng mesh titan
Đánh giá sau phâu thuật dựa trên tính thầm mỹ (bệnh nhân được chụp ảnh các tư thế 
thẳng: sự cân xứng của khuôn mặt, độ lồi cân xứng 02 bên nhãn cầu, sự hài lòng của người bệnh; Chức năng: thi lực, nhìn đôi, vận động nhãn cầu.

\section{KẾT QUẢ NGHIÊN CỨU}

Từ tháng 01/2019 đến 12/2020 tiến hành phẫu thuật tạo hình sàn hốc mắt sớm thì đầu cho 48 bệnh nhân. Tỷ lệ nam/nữ: 36/12, độ tuổi trung bình là 27 trong đó nhỏ nhất là 13 tuổi, lớn nhất là 56 tuổi.

Thời gian trung bình được phẫu thuật sau chấn thương là $5,43 \pm 5,67$ ngày. Thời gian nằm viện trung bình: 9,58 $\pm 8,07$ ngày.

Lâm sàng trước phẫu thuật: Bầm tím tụ máu phần mềm hốc mắt gặp ở $100 \%$ trường hợp; nhìn đôi: $8 / 48(16,66 \%)$; giảm và mất thị lực : 13/48 (27\%); liệt vận nhãn: 3/48 (12,5\%)

Bảng 1. Kêt quả chụp phim cắt lớp trước phẫu thuật

\begin{tabular}{|c|c|c|c|c|c|}
\hline & $\begin{array}{c}\text { Oộ nhô nhãn cầu } \\
\text { bên vỡ xương sàn } \\
\text { hốc mắt }\end{array}$ & $\begin{array}{c}\text { Độ nhồ } \\
\text { nhẫn cầu } \\
\text { bên lành }\end{array}$ & $\begin{array}{c}\text { Khoảng cách } \\
\text { trong của ổ mắt } \\
\text { bên vơ xương }\end{array}$ & $\begin{array}{c}\text { Khoảng cách } \\
\text { trong cúa ổ mắt } \\
\text { bên lành }\end{array}$ & $\begin{array}{c}\text { Phối hớp cùng } \\
\text { các vỡ xương } \\
\text { hàm mặt khác }\end{array}$ \\
\hline $\begin{array}{c}\text { Trung } \\
\text { bình }(\mathrm{mm})\end{array}$ & $13,2 \pm 4,14$ & $\begin{array}{c}16,61 \pm \\
2,81\end{array}$ & $39,83 \pm 3,44$ & $35,69 \pm 2,46$ & $100 \%$ \\
\hline
\end{tabular}

Bảng 2. Vật liệu tạo hìh ổ măt

\begin{tabular}{|c|c|c|}
\hline Vật liệu độn & Số lượng & Tỷ lệ \\
\hline Ghép xương & 16 & $33,34 \%$ \\
\hline Mesh titan & 21 & $43,75 \%$ \\
\hline Medpore & 11 & $22,91 \%$ \\
\hline Tống (n) & $\mathbf{4 8}$ & $\mathbf{1 0 0} \%$ \\
\hline
\end{tabular}

Đường vào qua bờ mi dưới 21/48 trường hợp, qua vết thương có sẵn 24/48 trường hợp, qua nội soi xoang hàm $3 / 48$ trường hợp.

Bảng 3. Kết quả sau phẫu thuật tạo hình sàn hốc mắt

\begin{tabular}{|c|c|c|}
\hline Đánh giá về & $\begin{array}{c}\text { Số } \\
\text { lượng } \\
(\mathrm{n}=48)\end{array}$ & $\begin{array}{l}\text { Tỷ lề } \\
\text { (\%) }\end{array}$ \\
\hline $\begin{array}{c}\text { Chức năng } \\
\text { Tốt (thị lực, cảm giác, vận động) } \\
\text { Thị lực giảm hoặc mất } \\
\text { Nhìn đôii } \\
\text { Mất hạn chễ vận động nhãn cầu } \\
\text { Dị cảm vuùng dà hốc mắt } \\
\text { Nhiếm trùng } \\
\text { Lộ chất liệu }\end{array}$ & $\begin{array}{c}29 \\
9 \\
3 \\
3 \\
4 \\
0 \\
0 \\
\end{array}$ & $\begin{array}{c}60,4 \\
18,7 \\
6,2 \\
6,2 \\
8,5\end{array}$ \\
\hline $\begin{array}{c}\text { Thấm mỹ̃ } \\
\text { Độ nhô nhãn câu } 02 \text { bên } \\
\text { Cân xứng } \\
\text { Không cân xứng (BN hài lòng với } \\
\text { kết quả) } \\
\text { Không cân xứng (BN có nhu câu } \\
\text { làm lại thì hai) } \\
\text { Cân xứng của khuôn mặt } \\
\text { Cân xứng } \\
\text { Không cân xứng (BN hài lòng với } \\
\text { kết quả) } \\
\text { Không cân xứng (BN có nhu cầu } \\
\text { làm lại thì hai Sứ hài lòng của } \\
\text { người bêênh } \\
\text { Rắt hài lìng } \\
\text { Hài lòng } \\
\text { Bình thường } \\
\text { Không hài lòng }\end{array}$ & $\begin{array}{c}38 \\
7 \\
3 \\
40 \\
5 \\
3\end{array}$ & $\begin{array}{c}79,2 \\
14,5 \\
6,3 \\
83,3 \\
10,5 \\
6,2\end{array}$ \\
\hline
\end{tabular}

\section{BÀN LUÂ̂N}

Tại khoa phẫu thuật tạo hình hàm mặt trước đây chúng tôi thường thực hiện tái tạo ổ mắt sau chấn thương khoảng 9 đến 12 tháng sau mổ cùng với mổ tháo nẹp vít. Tuy nhiên những năm gần đây chúng tôi thực hiện tái tạo sàn ổ mắt ngay sau chấn thương cho được kết quả khả quan. Tất cả trường hợp trong nghiên cứu đều được can thiệp sớm trước 2 tuần sau chấn thương. Đa số các tác giả cho rằng nên can thiệp sớm 2 tuần đầu sau chấn thương để tránh hiện tượng xơ hóa tổ chức, mặc dù thời điểm này mắt còn nề, các dấu hiệu như lõm ổ mắt, song thị chưa rõ ràng $[2,5]$. Ở cả 2 nhóm phẫu thuật sớm và muộn theo tác giả Nguyễn Hoàng Cương thì đều cải thiện nhưng số lượng bệnh nhân còn ít [1]. Tác giả Simon so sánh kết quả giữa 2 thời điểm can thiệp trước và sau 2 tuần thấy kết quả không có sự khác biệt [6]. Ý nghĩa quan trọng nhất là bằng chứng của tổn thương cơ học trong cơ hốc mắt gây ra chứng nhìn đôi Thứ hai là bằng chứng về chứng lõm mắt. Khi có vết sưng ban đầu ở chỗ chấn thương, bất kỳ phần lõm mắt mà rõ ràng đều chỉ ra sự biến dạng trầm trong. Nhiều tác giả cho rằng bất kỳ khuyết hổng nào mà lớn hơn $1 \mathrm{~cm} 2$ sẽ phải phẫu thuâtt bởi vì chúng chắc chắn sẽ lõm mắt về sau. Tác giả khác định lượng thông qua ảnh hóa $\mathrm{CT}$, kích thước tăng thực tế thể tích mắt so với bên không bị tổn thương. Thể tích này sau đó được sử dụng để đi vào những mối nguy hiểm của chứng lõ̃m mắt sau chấn thương. Với nghiên cứu của chúng tôi khi so sánh độ nhô nhãn cầu 02 bên (bên võ xương trung bình: $13,2 \pm 4,14 \mathrm{~mm}$; bên lành trung bình: $16,61 \pm 2,81 \mathrm{~mm}$ ) có sự khác biệt rõ rết trước phẫu thuật tạo hình sàn hốc mắt.

Chất liệu tái tạo sàn ổ mắt bao gồm: xương tự thân (thành trước xoang, xương mào chậu, 
bản ngoài xương ...), sụn tự thân, mesh titan, medpore... $[3,4,6]$. Trong nghiên cứu chúng tôi sử dụng chủ yếu mesh titan với 21 bệnh nhân, mảnh xương thành trước xoang hàm với 16 bệnh nhân, và 11 bệnh nhân sử dụng medpore (omnipore). Việc lựa chọn chất liệu sẽ được đánh giá trong mổ và tuỳ vào mức độ tổn thương. Với trường hợp võ̃ xương sàn hốc mắt ở mức độ nhẹ, kèm theo võ thành trước xoang hàm có mảnh xương đủ lớn có thể lót được sàn ổ mắt thì chúng tôi ưu tiên sử dụng xương tự thân, ở trường hợp võ̃ xương sàn hốc mắt mức độ nhẹ không có mảnh xương đủ lớn để ghép thì tấm Medpor là 1 lựa chọn tối ưu. Vỡ sàn hốc mắt lớn kèm theo tụt kẹt tổ chức hậu nhãn cầu xuống xoang hàm thì mesh titan là lựa chọn tốt nhất. Đối với miếng lót sàn ổ mắt là tấm Titan thì ưu điểm của Titan so với các loại chất liệu tổng hợp khác là có khả năng chịu lực lớn, dễ uốn cho vừa với khuôn của sàn ổ mắt. Tuy nhiên Theo Asamura, nhược điểm chung của các chất liệu tổng hợp là nguy cơ nhiễm khuẩn, đặc biệt là trong tạo hình ngay thì đầu, do ổ gãy thông với xoang hàm hoặc thông với vết thương ngoài da [4]. Tuy nhiên, chúng tôi không ghi nhận trường hợp nào nhiễm trùng sau mổ Omnipore (medpore) là vật liệu polyethylen dạng lỗ nhỏ li ti và là vật liệu được chứng minh là có khả năng kích thích được sự phát triển của mô và lắng đọng collagen vào các khe rỗng từ đó tạo ra được một phức hợp ổn định có khả năng chống nhiễm trùng và chịu được lực va đập, dễ uốn. Tuy nhiên đối vơi những trường hợp võ xương sàn hốc mắt phức tạp cần bù với thể tích lớn thì medpor không đủ, giá thành vật liệu cao $[7,8]$. Mảnh xương thành trước xoang được tạo hình trước khi lót vào sàn ổ mắt và được đặt vào giữa 2 thành của sàn ổ mắt. Medpor hay miếng titan được đặt vào sàn ổ mắt thường được cố định bằng cách khoan xương bắt vis, hoặc khoan xương khâu bằng chỉ tiêu chậm với trường hợp lót ổ mắt bằng Medpor. Cố định tốt vật liệu cấy ghép làm giảm nguy cơ cảm giác dị cảm sau mổ. Tất cả bệnh nhân của chúng tôi không có dị cảm sau mổ và lộ chất liệu do vật liệu di chuyển như các tác giả khác [2]. Về đường mổ đa số chúng tôi thực hiện đường mổ mi dưới mắt, ở 1 số bênh nhân có vết thương gò má chúng tôi gặp sẽ tiếp cận sàn ổ mắt qua vết thương tuy nhển không có bênh nhân nào biến chứng nhiễm trùng sau mổ.
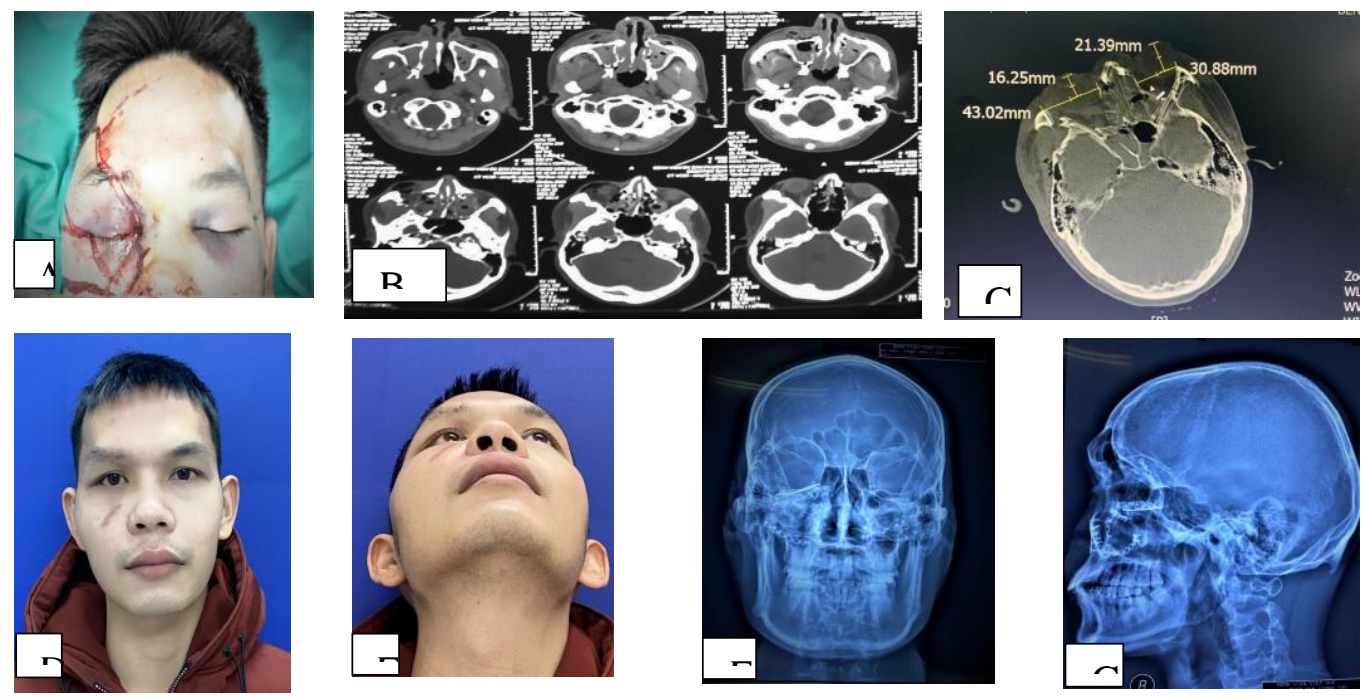

Hinh 3. A: Bn nam 29 tuổi, gãy xương hàm trên Lefort II, II, vỡ xương sàn hốc mắt phải.

B, C: Hình ảnh võ xương trên CT, đo độ nhô nhãn cầu trên phần mềm máy tính.

D, E: Hình ảnh sau phẫu thuật 2 tháng cân đối

Nhiều nghiên cứu cho thấy, việc tạo hình sớm sàn hốc mắt cho thây giảm hiện tượng teo lõm tổ chức hậu nhãn cầu là một trong những nguyên nhẩn chính gây hiện tượng lõm hốc mắt cho dù có được vá vỡ xương sàn hốc mắt thì hai. Với kết quả đạt cân xứng ổ mắt sau phẫu thuật đạt 79,2\%, mức độ hài lòng của bệnh nhân đạt
$85,4 \%$ của nghiên cứu đã cho thấy ưu điểm của phương pháp tạo hình sớm thì đầu.

\section{KẾT LUÂ̂N}

Võ sàn hốc mắt là một tổn thương phức tạp, ảnh hưởng tới chức năng cũng như thẩm mỹ của bệnh nhân. Tạo hình ổ mắt ngay ở thì đầu giúp 
bênh nhân tránh được nhiều di chứng và biến chứng. Việc lựa chọn chất liệu tạo hình phụ thuộc vào từng mức độ tổn thương.

\section{TÀI LIÊU THAM KHẢO}

1. Nguyễn Hoàng Cương và cộng sự (2014). Đánh giá kết quả phẫu thuât tao hình ổ mắt sau chấn thương tại bệnh viện Việt Đức. Kỷ yếu Hội nghi chấn thương chỉnh hình toàn quốc 2014.

2. Sedar Duzgun, Bahar Kayahan Sirkeci (2020). Comparision of post-operative outcoms of graft material used in reconstruction of blow- out fracture. Ulus Travma Acil Cerrahi Derg. 2020; 26(4): 538-544

3. Joseph JM, Glavas IP (2011). Orbital fractures; A reviwiew. Clincal Ophthalmology; 5:95-100.
4. Asmura $S$, Ikada $Y$, Matsunaga $K$, Wada $M$, Isogai $\mathbf{N}$ (2010). Treatment of orbital floor fracture uusing a periosteume polumer complex; Journal of Craniomaxillofacial Surgery; 38:197-203.

5. Courtney DJ, Thomas S, Whitfield PH (2000) Isolated orbital blow-out fracture: Survey and review. BR J Oral Maxillofac Surg; 38:496-503.

6. Simon GJ, Syed HM, McCann JD, Goldberg RA (2009). Early versus late repair of orbital blow-out fracture. Ophthalimic Surg Laser Imaging; 40:141-148.

7. Roth FS et al. (2010). Pearls of orbital trauma management. Serminars in Plastic Surgery; 24(4): 398-409.

8. Whitehouse R. et al (1994). Prediction of enophthalmos by computed tomography after'blow out'orbital fracture. British journal of ophthalmology. 78 (8), pp. 618-620.

\section{MộT Số KÍCH THƯớC CỦA DÂY CHẰNG CHÉO TRƯớC TRÊN PHIM CHỤP CộNG HƯởNG TỪ}

\section{TÓM TẮT}

Mục tiêu: Xác định các kích thước của dây chằng chéo trước trên phim chụp cộng hưởng từ. Đối tượng và phương pháp nghiên cứu: nghiên cứu hồi cứu mô tả cắt ngang 40 phim chup công hưởng từ (CHT)khớp gối của bệnh nhân được chẩn đoán không có tổn thương dây chằng chéo trước (DCCT) từ tháng 10/2018- tháng 6/2019, nhằm đưa ra các kích thước củAdcct. Kết quả: các bênh nhân có tuổi trung bình là 31,75 tuổi. Tỷ lệ nam nhiều hơn nữ, gối phải nhiêu hơn gối trái. Đo được chiêuu dài trung bình của DCCT trên mặt phẳng cắt đứng dọc là $36,63 \pm 2,15 \mathrm{~mm}$; trong đó của nam là $37,07 \pm 2,10 \mathrm{~mm}$; của nữ là 35,61 $\pm 2,00 \mathrm{~mm}$; gối phải là $36,76 \pm 2,21 \mathrm{~mm}$; gối trái là $36,39 \pm 2,10 \mathrm{~mm}$. Đường kính trung bìnhtai điểm giữa của DCCT trên mặt cắt đứng dọc là $9,19 \pm 1,84 \mathrm{~mm}$, trong đó của nam là $9,44 \pm 1,85 \mathrm{~mm}$; của nữ là $8,60 \pm 1,73$ mm; gối phải là 9,08 $\pm 2,00$ mm; gối trái là $9,40 \pm 1,57 \mathrm{~mm}$. Kết luận: Qua quá trình nghiên cứu đã đo được chiều dài DCCT và đường kính tại điểm giữa DCCT. So sánh được các kích thước giữa hai giới, hai bên gối.

Từ khóa: Dây chằng chéo trước, cộng hưởng từ

\section{SUMMARY}

STUDY ON MEASUREMANT OF THE ANTERIOR CRUCIATE LIGAMENT (ACL) USING MRI

Purpose: Measurement of the anterior cruciate ligament (ACL) using MRI. Subjects and methods:

*Trường Đại học Điều dưỡng Nam Định

Chịu trách nhiệm chính: Nguyễn Thị Hồng Yến

Email: yendhdd@gmail.com Tel: 0976464219.

Ngày nhân bài: 12/6/2021

Ngày phản biên khoa hoc:5/7/2021

Ngày duyệt bài 26/7/2021

\section{Nguyễn Thị Hồng Yến*}

Restrospectively study 40 cases native anterior cruciate ligament using MRI from October/2018 to June/2019,the research ismeasurement of the anterior cruciate ligament using MRI. Results: The average age is 31,75 . Male prominent, right knee prominent too. In the sagittal plane,the average $A C L$ length was $36,63 \pm 2,15 \mathrm{~mm}$; the average in males were $37,07 \pm$ $2,10 \mathrm{~mm}$; the average in females were $35,61 \pm 2,00$ $\mathrm{mm} ; 36,76 \pm 2,21 \mathrm{~mm}$ in right knee; $36,39 \pm 2,10$ $\mathrm{mm}$ in left knee. In the sagittal plane, the average $\mathrm{ACL}$ width was $9,19 \pm 1,84 \mathrm{~mm}$; the average in males were $9,44 \pm 1,85 \mathrm{~mm}$; the average in females were 8,60 $\pm 1,73 \mathrm{~mm} ; 9,08 \pm 2,00 \mathrm{~mm}$ in right knee; $9,40 \pm$ $1,57 \mathrm{~mm}$ in left knee. Conclusion:the result of the research is the average $A C L$ length and the average $\mathrm{ACL}$ width. They compared between left and right knees and between genders.

Keywords. Anterior cruciate ligament,MRI

\section{I. ĐĂT VẤN ĐỀ}

Dây chằng chéo trước là thành phần quan trọng đảm bảo sự vững chắc về mặt động học theo chiều trước sau của khớp gối. Chấn thương khớp gối là một chấn thương rất hay gặp và tổn thương thường găp nhất trong chấn thương này là tổn thương đứt hay đụng dập DCCT [1]. Phẫu thuât tạo hình dây chằng chéo trước đã trở nên phổ biến và hiện nay được thực hiện hầu hết qua phẫu thuật nội soi. Để đáp ứng đòi hỏi ngày càng cao về hiểu biết giải phẫu DCCT trong chẩn đoán, điều trị và can thiệp phẫu thuật tạo hình lại dây chằng đạt những kết quả tốt, ngày nay chúng còn được quan tâm nghiên cứu dựa trên những kỹ thuật hiện hình ngày càng hiện đại hơn. Chụp cộng hưởng từ là một phương pháp thăm dò không xâm lấn rất ưu việt, cho phép tái 